LICENÇA CC BY: Artigo distribuído sob os termos Creative Commons, permite uso e distribuição irrestrita em qualquer meio desde que o autor credite a fonte original.

\title{
PERFIL DISCENTE NAS LICENCIATURAS EM CIÊNCIAS E EM QUÍMICA NA UECE E FORMAÇÃO PROFISSIONAL
}

STUDENT PROFILE IN UNDERGRADUATE COURSES IN SCIENCE AND CHEMISTRY AT UECE AND TEACHER EDUCATION PERFIL DEL ESTUDIANTE DE LICENCIATURA EN CIENCIAS Y QUÍMICA EN LA UECE Y FORMACIÓN PROFESIONAL

Francisco Ranulfo Freitas Martins Júnior ${ }^{1}$

Eloisa Maia Vidal'

'Programa de Pós-Graduação em Educação, Universidade Estadual do Ceará, Fortaleza, CE, Brasil.

Artigo recebido em: 23/06/2020

Aprovado em: 15/11/2020

Resumo: Este artigo objetiva apresentar e analisar informações sobre o perfil dos ingressantes e concludentes nos cursos de licenciatura curta em Ciências e licenciatura plena em Química na Universidade Estadual do Ceará (UECE), desde seu surgimento em 1976 até 2018. Utiliza o estudo de caso do tipo único e integrado, tendo sido analisados dados quantitativos referentes aos seis campi da UECE que ofertam os respectivos cursos. A trajetória estudantil foi mapeada pelo trabalho com tais dados, contidos em planilha de Excel fornecida pelo Departamento de Informática da instituição, na qual foi aplicada uso de filtros e análise por meio de estatística descritiva. Os resultados encontrados evidenciam que estes cursos sofrem com percalços que atingem a área de Ciências e Matemática em relação à dificuldade de formar professores. Há evidências de altos percentuais de abandono, que superam os percentuais de formados, tanto no período de oferta da licenciatura curta, quanto no período subsequente. Registra-se, no entanto, uma modificação no perfil de procura pela formação inicial, quando o percentual de mulheres se sobrepõe ao de homens no curso atual. Observa-se também modificações na cartografia da oferta, com o aumento da interiorização após a plenificação da licenciatura.

Palavras-chave: Perfil discente; Licenciatura em Química; Formação de professores.

\begin{abstract}
This paper aims to present and analyze information about the profile of freshmen and senior college students on the Initial Teacher Training courses in Sciences and the full qualification major in Chemistry at Ceará State University (UECE) from its creation in 1976 until 2018.This research uses a case study of the unique, integrated type, after analyzing quantitative data on the six UECE campi that offer these courses. The student career was mapped by analyzing these data, contained in the Excel spreadsheet provided by the Information department of the institution. Filters were applied to the data, and analysis using descriptive statistics. The results show that these courses suffer from problems that affect the area of Sciences and Mathematics in relation to the difficulty of educating teachers. There is evidence of high dropout rates, surpassing those of the graduates, both in the
\end{abstract}


initial teacher training course and in the subsequent period. However, a change is seen in the profile of demand for initial training, with the percentage of women on the current course overtaking that of men. Changes are also seen in the cartography of the offer, with an increase in internalization after the graduation.

Keywords: Student profile; Degree in Chemistry; Teacher education.

Resumen: Este artículo tiene como objetivo presentar y analizar información sobre el perfil de los estudiantes de primer curso y egresados de la carrera de formación Inicial de profesores de ciencias y de profesores de química con titulación completa en la Universidad Estatal de Ceará (UECE), desde su creación en 1976 hasta 2018. En el presente estudio se ha utilizado el estudio de caso del tipo único e integrado, también se han analizado los datos cuantitativos de seis campus de la UECE que ofrecen los cursos mencionados anteriormente. La carrera de los estudiantes fue mapeada con los datos encontrados y recogidos en una hoja de cálculo de excel dadas por el Departamento de Informática de la institución, en la que se aplicó el uso de filtros y el análisis mediante el uso de estadísticas descriptivas. Los resultados encontrados muestran que estos cursos tienen problemas que afectan al área de ciencias y matemáticas en relación a la dificultad de formar a los profesores. Hay indicios de altos porcentajes de abandono, que superan los porcentajes de graduados, tanto en el curso de formación inicial de los profesores como en el período siguiente. Sin embargo, se observa un cambio en el perfil de la demanda de formación inicial, cuando el porcentaje de mujeres supera al de los hombres en el curso actual. También hay cambios en la cartografía de la oferta, con un aumento de la internalización después de la graduación.

Palabras clave: Perfil del estudiante; Licenciado en Química; Formación de profesores.

\section{Introdução}

A Universidade Estadual do Ceará (UECE) é uma instituição multicampi criada no fim dos anos 1970 pela fusão de um conjunto de faculdades isoladas que existiam no estado do Ceará. No seu processo de institucionalização, a UECE tem priorizado os cursos de formação de professores, tanto na capital como nas unidades do interior, sendo uma das instituições públicas de ensino superior do estado que mais forma professores para a educação básica.

A licenciatura curta em Ciências ${ }^{1}$ foi o primeiro curso criado depois da institucionalização da universidade, funcionando tanto na capital como nos campi do interior do estado. Este curso procurava atender a formação de professores apontada pela Lei n 5.692/71 (BRASIL, 1971), estabelecida à época da ditadura civil-militar e que reestruturou o ensino e criou o $1^{\circ}$ grau com oito anos de escolarização e o $2^{\circ}$ grau, com três anos.

Com cinco semestres de duração, o curso habilitava em ciências para a docência nos anos finais do $1^{\circ}$ grau (conhecido anteriormente como ginasial) e proporcionava uma segunda habilitação em licenciatura plena específica, com um ano de duração, em Matemática, Química, Física e Biologia, que permitia o exercício da docência no $2^{\circ}$ grau, situação que perdurou até o fim dos anos 1990, com a publicação da Lei n 9.394/96 (BRASIL, 1996). Na UECE, as formações das habilitações não funcionaram na sua integralidade e nem todas começaram a oferta ao mesmo tempo, iniciando com Matemática, depois Química e Física e, mais tarde, Biologia. 
Em algumas unidades do interior, as habilitações nem chegaram a funcionar. Em 1998, já sob as orientações da nova LDB, é criado o curso de licenciatura plena em Química, primeiro no campus da capital cearense (Fortaleza) e depois em cinco unidades da UECE localizadas no interior do estado: 1) Faculdade de Educação, Ciências e Letras do Sertão Central (Quixadá) em 1998; 2) Faculdade de Educação de Itapipoca em 2000; 3) Centro de Educação, Ciências e Tecnologia da Região do Inhamuns (Tauá) em 2000; 4) Faculdade de Filosofia Dom Aureliano Matos (Limoeiro do Norte) em 2001; 5) Faculdade de Educação de Crateús em 2001.

Considerando a história dos cursos de licenciatura curta em Ciências e licenciatura plena em Química da UECE e a situação acadêmica dos estudantes desde seu surgimento em 1976 até 2018, este artigo tem o objetivo de apresentar e analisar informações sobre o perfil dos ingressantes e concludentes nos dois cursos. O método de pesquisa foi o estudo de caso do tipo único e integrado (YIN, 2015), tendo sido analisados dados quantitativos referentes aos seis campi da UECE que ofertam os respectivos cursos. A trajetória estudantil foi mapeada pelo trabalho com dados a partir de planilha de Excel, obtidas junto ao Departamento de Informática (DI) da instituição, na qual foi aplicada uso de filtros e análise por meio de estatística descritiva. Vale destacar que a implicação da trajetória estudantil na formação de professores no estado do Ceará também foi motivo de análise neste estudo, sendo elaborada com base na pesquisa documental, conforme orienta Gil (2017).

A próxima seção apresenta um breve histórico sobre os cursos de licenciatura na área de Ciências Naturais em função de sua capacidade de formar licenciados, estimando a demanda de profissionais para a educação básica. Em seguida, é apresentado o caso da licenciatura plena em Química da UECE; a penúltima seção discorre sobre a trajetória dos estudantes desde a criação até o ano de 2018, narrando implicações destes cursos na formação do professorado. As considerações finais apresentam o cotejo entre trajetória e implicações.

\section{A senda tortuosa no itinerário formativo na área de Ciências Naturais}

Apesar da necessidade de professores licenciados na área de Ciências Naturais para ensinar as disciplinas científicas na educação básica, o Brasil registra dificuldades históricas na formação desses profissionais, seja pela baixa quantidade de formados ou pela qualidade da formação concedida. Após a publicação da LDB n 9.394/96, a formação de professores para atuar na educação básica passou a exigir graduação na modalidade licenciatura plena, e ficou restrita às instituições de ensino superior (IES). Se por um lado essa nova base legal buscou qualificar profissionais para a educação básica, por outro, agudizou a carência de docentes que atendessem essas novas exigências.

Sampaio et al. (2002) realizaram um dos primeiros trabalhos baseado em levantamento estatístico de professores que atuam na educação básica, tendo como fonte dados dos censos deste nível de ensino e da educação superior, comparando os números de licenciados com 
os de professores do ensino fundamental e médio nos anos de 1996 e 2001, bem como estimando a carência destes profissionais para o ano de 2006. Eles verificaram que, embora o Brasil tenha aumentado a oferta de vagas em cursos de licenciatura, inclusive os da área de Ciências Naturais, estes continuavam com vagas ociosas após processos seletivos, o que já evidenciava a baixa atratividade da carreira docente.

Num período em que as matrículas da educação básica aumentaram significativamente (anos 1990 e 2000), os cursos de formação de professores também tiveram sua oferta ampliada; mas ainda assim persistiam excedentes de vagas em muitas das licenciaturas, especialmente as que formam professores para lecionar disciplinas científicas. Os autores mostram que a demanda estimada de professores de Biologia, Física e Química para atender a educação básica no ano de 2002 era de 95.152 profissionais no ensino fundamental e 70.542 no ensino médio, sendo que somente 74.069 estudantes se licenciaram no período 1990 - 2001.

Também analisando dados do Censo da Educação Superior, Jesus, Araújo e Vianna (2014) constataram que a demanda por professores de Química no ensino médio no Brasil para o ano de 2002 só conseguiu ser atingida em 2012, ou seja, uma década depois. Importante salientar que, nesse período de 10 anos, o crescimento da oferta de ensino médio já indicava a necessidade de uma maior quantidade de professores de Química, mantendo assim o ciclo de carência.

Assim como registrado por Sampaio et al. (2002), alguns estudos têm evidenciado que o aumento do número de vagas destinadas a cursos de licenciatura na área de Ciências Naturais é, sozinha, ineficaz para sanar o deficit de professores que atuam na educação básica no ensino dessas disciplinas (ARAÚJO; VIANNA, 2011; LAMBRECHT; ZARA, 2017; RABELO; CAVENAGHI, 2016; SÁ; SANTOS, 2011; JESUS; ARAÚJO; VIANNA, 2014). Eles destacam que, no combate à escassez de professores dessa área, são necessárias medidas complementares à ampliação das vagas, como iniciativas de políticas educacionais de formação e atuação no ensino, reverberando em programas de bolsa na licenciatura e maior articulação entre universidade e escola no sentido de potencializar a profissão docente.

Trabalhando de modo independente, Araújo e Vianna (2011) e Lambrecth e Zara (2017) publicaram estudos que, além de confirmar a carência de professores de Ciências e Matemática na educação básica, dimensionam a quantidade baixa de licenciados nessas áreas, considerando o período de quase duas décadas (2000 - 2018). Eles frisam que, assim como é importante identificar e discutir a evasão de estudantes das licenciaturas, é necessário entender esse fenômeno.

Observando o cenário nacional e tomando por recorte o período 2000 - 2007, os primeiros autores apresentam a evolução do número de licenciandos (pública e privada, presencial e a distância) na área de Ciências e Matemática, dimensionando a carência de professores dessas áreas para atuar na educação básica. Eles puderam constatar que, embora a oferta de vagas para estes cursos tenha sido ampliada, o número de concluintes (117.096) pouco superou a quantidade necessária de professores para o ano de 2002 (105.812), identificada pelo Ministério 
da Educação (BRASIL/MEC, 2007). Endossando essa problemática, é importante salientar que nem todos os licenciados optam por atuar na docência.

Lambrecth e Zara (2017) realizaram estudo com enfoque nas áreas de Física e Química e replicaram os mesmos cálculos estatísticos para analisar o período 2008 - 2015. Assim como registrado no período 2000 - 2007, constataram que não houve crescimento significativo na oferta de vagas para os cursos presenciais nas referidas áreas em relação à evolução do ensino superior no Brasil nos sete anos considerados. Outro dado relevante é o crescimento de concluintes das licenciaturas em Física e Química (presenciais) no período 2008 - 2015, respectivamente $26 \%$ e $60 \%$, embora seja desproporcional à ampliação do número de vagas no período. Essa constatação aponta para uma melhoria na taxa de evasão em razão da "reestruturação curricular dos cursos, o Programa Institucional de Bolsa de Iniciação à Docência (Pibid), programas de Iniciação Científica e ações afirmativas como bolsas de permanência" (LABRECTH; ZARA, 2017, p. 165), o que representa um alento à formação de professores nessas duas licenciaturas.

Mesmo sendo possível aferir a demanda de professores da educação básica e estimar o número de licenciados para dimensionar uma carência, é difícil analisar e definir uma demanda real, pois, além de nem todos licenciados se efetivarem como professores, há poucos recursos que permitem delinear trajetórias formativa e profissional desses sujeitos. Pensando nessa problemática, Rabelo e Cavenagui (2016) realizaram um trabalho audacioso sobre a formação de docentes no ensino básico no Brasil, tendo por sujeitos licenciandos e docentes da área de Ciências e Matemática. Utilizando dados longitudinais dos censos da Educação Básica e Educação Superior, os autores elaboraram indicadores educacionais que permitiram descrever, no quinquênio 2009 - 2013, percursos acadêmicos (Indicador 1 - Conclusão na Educação Superior) e profissional (Indicador 2 - Permanência de Docentes na sala de aula).

Sabendo que a relação quantitativa ingressos/concluintes na licenciatura não é rígida, pois os censos educacionais no País não disponibilizam dados sobre a permanência de licenciandos no curso e de professores na docência, Rabelo e Cavenaghi (2016) trabalharam com códigos de identificação pessoal (ID) desses sujeitos, cadastrados junto às plataformas censitárias. Após análise do Indicador 1, constataram taxas de conclusão baixas considerando os licenciados que ingressaram nos cursos em 2009, quais sejam: Biologia (42,6\%), Matemática (34,1\%), Química (33,9\%) e Física (20,5\%). A análise do indicador 2 possibilitou que os autores verificassem, com relação aos docentes, comportamento semelhante ao dos licenciandos, pois a retenção anual destes profissionais em sala de aula foi inferior a 50\%.

A correlação dos dois indicadores permitiu que Rabelo e Cavenagui (2016) inferissem que, para o contexto contemporâneo da educação básica, tomando como parâmetro a área de Ciências e Matemática, e avaliando os baixos resultados destes indicadores, há dificuldade de aumento da oferta de docentes em face da baixa conclusão de alunos nas licenciaturas, levando em conta também o aumento no tempo de conclusão da licenciatura e a baixa permanência de docentes na regência das disciplinas científicas. 
Com relação à disciplina de Química, Sá e Santos (2011) e Jesus, Araújo e Vianna (2014) realizaram trabalhos que endossam a estimativa de docentes de Química da educação básica perante as quantidades de licenciados em Química, no Brasil, no período 2000 - 2012. Em conformidade ao contexto da área de Ciências e Matemática, a educação básica no Brasil é marcada por deficit de professores de Química. Sá e Santos (2011) destacam que esta carência, iniciada pela incapacidade das IES de formar estes profissionais em número suficiente para atender a demanda da educação básica, não se deve à escassez de cursos de formação inicial de professores de Química, mas à baixa procura e alta evasão nestes.

Analisando dados estatísticos que mostram a realidade brasileira da licenciatura em Química (vagas, candidatos, ingressos e vagas ociosas, matrículas, concluintes e taxas de evasão) - pública e privada, presencial e à distância -, Jesus, Araújo e Vianna (2014) demonstram a evolução de 2000 a 2014, qual seja: i) aumento de 759\% de vagas na modalidade presencial e $318,8 \%$ na modalidade a distância; ii) crescimento do número de candidatos - $1.089 \%$ por vagas presenciais e $8,2 \%$ a distância; iii) crescimento de vagas ociosas $(1.385 \%$ presencial e $69,7 \%$ a distância) e ingressos na modalidade presencial (525,3\%); iv) aumento de 960\% de matrículas na modalidade presencial e 95,8\% a distância; v) aumento de $1.739 \%$ concluintes na modalidade presencial; vi) taxas de evasão do curso superiores às observadas em todos os cursos de graduação do Brasil. Apesar da significância dos percentuais atribuídos ao curso (exceto evasão), considera-se "[...] a necessidade de se repensar e viabilizar políticas públicas voltadas ao ingresso e permanência dos jovens na Licenciatura em Química, pois a simples ampliação das vagas pode não ser suficiente" (JESUS; ARAÚJO; VIANNA, 2014, p. 11).

A atualização dos números relativos à licenciatura em Química no Brasil é apresentada no Quadro 1, constituído por dados da Sinopse Estatística da Educação Superior, do Instituto de Estudos e Pesquisas Educacionais Anísio Teixeira (Inep). A análise desses dados pode dimensionar a formação inicial de professores de Química no Brasil, tanto por oferta pública como privada, e ainda contribuir na estimativa da demanda de professores de Química na educação básica.

Quadro 1 - Números relativos à formação docente em Química no Brasil no triênio 2016 $-2018$

\begin{tabular}{|l|l|l|l|l|}
\hline \multicolumn{5}{|c|}{ Formação inicial } \\
\hline Variável & 2016 & 2017 & 2018 & Total \\
\hline Vagas ofertadas & 68.848 & 72.467 & 86.895 & 228.210 \\
\hline Candidatos & 106.006 & 100.213 & 85.286 & 291.505 \\
\hline Ingressos & 11.904 & 14.246 & 15.070 & 41.220 \\
\hline Vagas ociosas & 56.944 & 58.221 & 71.825 & 186.990 \\
\hline Matrículas & 36.112 & 37.769 & 37.881 & 111.762 \\
\hline Concluintes & 3.978 & 4.065 & 4.149 & 12.192 \\
\hline
\end{tabular}

Fonte: Elaborado pelos autores com base nos dados das Sinopses Estatísticas da Educação Superior (INEP, 2017, 2018, 2019). 
Em 2018, 193 IES ofertaram 333 cursos de formação docente em Química. Com exceção da procura pela licenciatura em Química, que diminuiu no triênio considerado, como indicado pela baixa concorrência $(1,28)$, as demais variáveis apresentaram leve aumento, com destaque para as vagas ofertadas, ingressos, matrículas e concluintes. Chama a atenção também o crescimento das vagas ociosas, o que aponta para a baixa procura pelo curso, fato comprovado pela quantidade de candidatos, que cai a cada ano.

Os 12.192 licenciados em Química no período 2016 - 2018 representam uma quantidade aquém da estimativa de 26.848 professores exclusivos de Química para atender a demanda do ensino médio regular em 2013, em uma jornada de trabalho de 40 horas semanais (INEP, 2015). Ou seja, cinco anos depois, o País não conseguiu formar nem metade dos docentes que precisava em 2013, revelando a persistência da carência deste tipo de profissional.

Feitas essas considerações sobre o cenário de formação de professores de Química no Brasil, a próxima seção apresenta o caso das licenciaturas em Ciências e em Química na UECE, tomando como referência o ano de 1976 e seguindo até 2018.

\section{O caso das licenciaturas curta em Ciências e plena em Química da UECE: procedimentos metodológicos}

Para este estudo, a UECE foi tratada como um caso único da formação de professores de Ciências/Química, e os seus seis campi (Itaperi, Feclesc, Facedi, Cecitec, Fafidam e Faec) como unidades integradas de análise. A escolha do caso único se deu pela possibilidade de estudo longitudinal (YIN, 2015) da formação docente em Ciências/Química, desde os primórdios até o ano de 2018. De posse do caso escolhido, optou-se por uma abordagem de pesquisa quantitativa, norteadora da coleta de dados quantitativos (YIN, 2015) sobre a situação acadêmica e outras variáveis atinentes ao perfil dos sujeitos, sendo estas os insumos principais das implicações almejadas. A trajetória estudantil foi analisada com utilização da base de dados produzida pelo DI da UECE, elaborada a partir de oito variáveis não métricas, organizadas em planilha do software Microsoft Office Excel ${ }^{\circledR}$, considerando: 1) curso; 2) habilitação; 3) ano de ingresso; 4) situação do aluno; 6) semestre em que se graduou; 7) sexo; 8) unidade ofertante.

As oito variáveis foram analisadas tanto de forma independente, para obtenção de frequência numérica, como de forma relacionada, para obtenção de características da população de estudantes dos cursos, sendo as mais relevantes destas: a) estudantes por sexo; b) estudantes por unidade da UECE que ofereceu o curso de licenciatura curta em Ciências e oferta o curso de licenciatura plena em Química; c) situação acadêmica dos estudantes nos cursos.

As análises independentes e relacionadas foram realizadas por testes estatísticos através do software JASP ${ }^{\circledR}$ 0.8.6.0. Os testes para obtenção de frequência numérica foram realizados por meio do recurso Descriptives - Descriptive Statistics, enquanto os testes para obtenção das características foram realizados por meio do recurso Frequencies - Contingency Tables. 
As implicações da trajetória estudantil na formação do professorado foram tecidas com base nas pesquisas documental e bibliográfica, pois de acordo com o que afirma Gil (2017) sobre este tipo de pesquisa, é possível explorar uma gama de acontecimentos sobre determinado assunto, considerando dois tipos de dados: primários (documentos) e secundários (livros, artigos, etc.).

Os dados analisados neste artigo estão organizados em dois períodos. O primeiro considera desde o início do curso de licenciatura curta em Ciências com habilitações, em 1976, quando os ingressantes cursavam cinco semestres, com o propósito de se habilitarem para o ensino da disciplina de Ciências Físicas e Biológicas nos quatro anos finais do $1^{\circ} \mathrm{grau}$ (correspondente do $6^{\circ}$ ao $9^{\circ}$ ano, atualmente) e podiam escolher uma habilitação (Física, Química, Biologia, Matemática) para a docência no $2^{\circ}$ grau (atualmente, ensino médio). Esse modelo de formação manteve-se em oferta até $1997^{2}$. O segundo é caracterizado pelo ingresso no curso de licenciatura plena em Química, já sob os auspícios da LDB de 1996, momento também marcado pela ampliação da oferta de ensino fundamental e médio no estado do Ceará.

\section{A trajetória estudantil nos cursos em dois períodos: $1976-1997$ e $1998-2018$}

Inserida no contexto dos movimentos educacionais que se avolumaram nas décadas de 1970 e 1980, a UECE foi criada em 1975, por uma junção de faculdades isoladas existentes no estado do Ceará, com o propósito de atender demandas da sociedade cearense e, desde sua criação, se destaca na área de formação de professores (FARIAS et al., 2011).

Em 1976, a licenciatura curta em Ciências passa a existir na UECE e é sucedida, alguns anos depois, pelas habilitações em Matemática, Química, Física e Biologia, respectivamente, assumindo protagonismo na formação de professores da área de Ciências Naturais no território cearense, seguindo os normativos estabelecidos em âmbito nacional. Assim, tanto a licenciatura curta em Ciências como as suas habilitações viveram todos os percalços advindos das legislações do regime civil-militar e do período de redemocratização.

Com a publicação da LDB em 1996, a partir de 1998 a UECE cria as licenciaturas plenas específicas para as disciplinas de Matemática, Química, Física e Biologia e extingue a licenciatura curta em Ciências com habilitações. Nesse período, a expansão da universidade para o interior do estado faz com que parte dessas licenciaturas inicie seu funcionamento nas unidades localizadas fora da capital, ampliando a iniciativa de formação de professores para a educação básica e desenhando uma nova cartografia desta formação. 


\section{O período 1976 - 1997: ampliando a oferta na capital e chegando ao interior}

É importante destacar que, a partir de 1971, com a instituição da Lei no 5.692/71, o ensino secundário ( $2^{\circ} \mathrm{grau}$ ) brasileiro demanda professores habilitados para lecionar disciplinas específicas como Biologia, Física, Matemática e Química. De acordo com o artigo 29 desta lei, a formação docente para o ensino de $2^{\circ}$ grau deveria ser feita em diferente nível de complexidade, de acordo com a região do País, visando às especificidades deste grau de ensino, as características das disciplinas da área de Ciências e Matemática e o desenvolvimento cognitivo de estudantes.

Os dados apresentados no Gráfico 1 mostram a situação acadêmica dos ingressantes na UECE entre os anos 1976 - 1997, período marcado pela oferta da licenciatura curta em Ciências, com habilitações em Matemática, Química, Física e Biologia.

Gráfico 1 - Situação acadêmica dos alunos de licenciatura curta em Ciências e habilitações no período 1976 - 1997

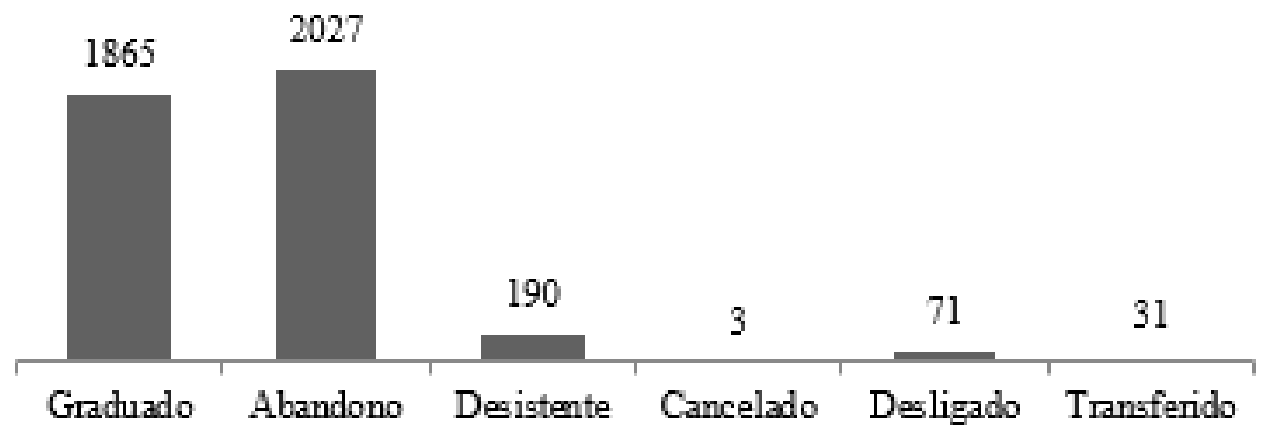

Fonte: Elaborado pelos autores com base nos dados fornecidos pelo DI da UECE (2018).

Do total de 4.187 ingressantes em 22 anos (1976 - 1997), 1.865 (44,5\%) conseguem se formar, 2.027 (48,4\%) abandonam, 190 (4,5\%) desistem e 2,5\% encontram-se em situação de cancelado, desligado ou transferido, confirmando o alto fenômeno de evasão já neste período, situação similar à que foi apresentada por Jesus, Araújo e Vianna (2014). Os dados mostram que a taxa média de admissão anual é de 190 alunos, fato que pode ser explicado pela pequena quantidade de docentes existentes na universidade e distribuídos nas unidades do interior. Chama a atenção, no entanto, o fato de menos de $50 \%$ dos ingressantes conseguirem se formar, mesmo num curso cuja duração era de cinco semestres. Dos 1.865 formados, 1.118 (59,9\%) obtêm a licenciatura curta, que habilita apenas para o ensino de Ciências Físicas e Biológicas nas séries finais do $1^{\circ} \mathrm{grau}$, embora a oferta de ensino médio no estado do Ceará 
já totalizasse mais de 200.000 alunos em 1997 (INEP, 1998). Os resultados deste período exemplificam a incapacidade de cursos de licenciatura em Ciências em formar licenciados em quantidade ideal, realidade também persistente no século XXI (SÁ; SANTOS, 2011; ARAÚJO; VIANNA, 2011). Observando o final deste período, é importante destacar que a licenciatura no Brasil foi um dos cursos com maior crescimento no número de ingressantes, o que não quer dizer que teve um maior número de formados (SAMPAIO et al., 2002).

Embora seja difícil estimar a quantidade necessária de docentes para atuar na educação básica antes dos anos 2000, por falta de dados nacionais que diferencie bacharelado e licenciatura (JESUS; ARAÚJO; VIANNA, 2014), como os divulgados nos últimos censos escolares pelo MEC, o secretário de Educação do estado do Ceará no período 1995 - 2001 constatou uma redução de $6,9 \%$ de professores não habilitados para o ensino (NASPOLINI, 2001), num momento em que no Ceará esteve em franco crescimento a oferta da educação básica, evidenciando assim que, embora de forma parcial e limitada, a formação de professores pela UECE dá uma contribuição positiva ao sistema de educação básica do estado.

Quando analisada a participação por sexo na licenciatura curta em Ciências da UECE, observa-se que, entre os ingressantes, $68,3 \%$ são do sexo masculino e $31,7 \%$ do feminino, percentuais que se mantêm semelhantes ao se observar o número de formados, como é possível constatar no Gráfico 2.

Gráfico 2 - Ingressantes e graduados por sexo no período 1976 - 1997

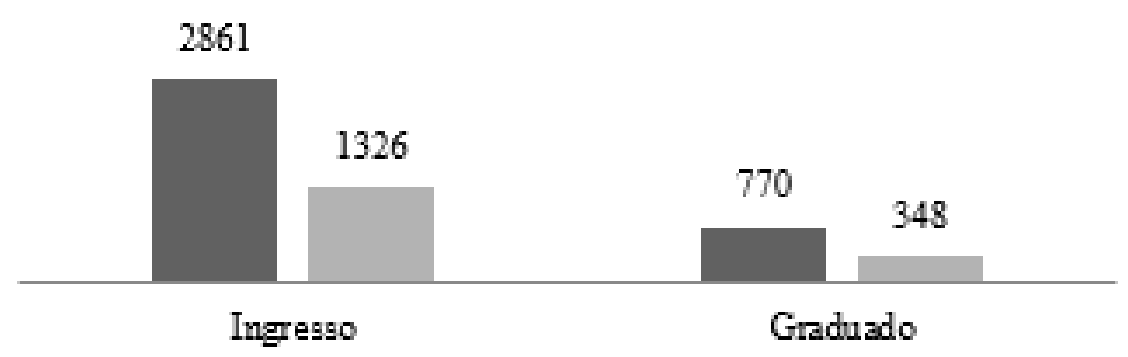

n Masculino $n$ Feminino

Fonte: Elaborado pelos autores com base nos dados fornecidos pelo DI da UECE (2018).

Essa característica remonta a criação da universidade no Brasil em 1930, em que prevalece a procura de candidatos do sexo masculino por curso de graduação nas áreas de Ciência e Tecnologia. Os dados do Gráfico 2 refletem essa situação, uma vez que mais do que o dobro de ingressantes e graduados são homens, evidenciando a baixa participação feminina nos cursos superiores relacionados às áreas de conhecimento de ciências exatas e da terra e de engenharias. Analisando o cenário nacional sobre a presença nos cursos universitários e de pós-graduação, Guedes (2008) identificou que foram necessários 30 anos (1970 - 2000) para reverter a sobrepujança de homens no ambiente acadêmico, inclusive com a entrada expressiva de mulheres em cursos tradicionalmente masculinos. 
No que se refere à cartografia da formação neste período, o Quadro 2 apresenta dados sobre ingresso, formação e sexo em todas as unidades da UECE que ofertavam o curso.

Quadro 2 - Ingressantes e formados por sexo, licenciatura curta em Ciências por unidade da UECE no período 1976 - 1997

\begin{tabular}{|c|c|c|c|c|c|c|c|}
\hline \multirow{2}{*}{ Unidade } & \multirow{2}{*}{ Ingresso } & \multirow{2}{*}{ Formados } & \multirow{2}{*}{$\begin{array}{l}\% \text { Forma- } \\
\text { dos }\end{array}$} & \multicolumn{2}{|l|}{$\begin{array}{l}\text { Quantidade } \\
\text { Formados } \\
\end{array}$} & \multicolumn{2}{|c|}{$\begin{array}{l}\text { Percentual For- } \\
\text { mados }\end{array}$} \\
\hline & & & & Masculino & Feminino & $\%$ Masc. & $\begin{array}{l}\% \\
\text { Fem. }\end{array}$ \\
\hline Fortaleza & 3.591 & 1.612 & $44,9 \%$ & 1.114 & 498 & $69,1 \%$ & $30,9 \%$ \\
\hline $\begin{array}{l}\text { Limoeiro } \\
\text { do Norte }\end{array}$ & 404 & 128 & $31,7 \%$ & 63 & 65 & $49,2 \%$ & $50,8 \%$ \\
\hline Quixadá & 121 & 81 & $66,9 \%$ & 39 & 42 & $48,1 \%$ & $51,9 \%$ \\
\hline Tauá & 71 & 44 & $62,0 \%$ & 22 & 22 & $50,0 \%$ & $50,0 \%$ \\
\hline Total & 4.187 & 1.865 & $44,5 \%$ & 1238 & 627 & $66,4 \%$ & $33,6 \%$ \\
\hline
\end{tabular}

Fonte: Elaborado pelos autores com base nos dados fornecidos pelo DI da UECE (2018).

Observa-se que a concentração de ingressantes $(85,7 \%)$ e formados $(86,4 \%)$ se dá na capital, e apenas três unidades do interior oferecem o curso de licenciatura curta em Ciências - Limoeiro do Norte, Quixadá e Tauá -, como mostra o Quadro 2. Os dados também permitem constatar que, juntas, todas as unidades conseguiram formar $44,5 \%$ dos ingressantes, com destaque para a unidade de Quixadá, que formou 66,9\%, e Tauá, com 62,0\%. Quando observado o número de formados por sexo, prevalece a formação de homens em Fortaleza (69,1\%), sendo que nas unidades do interior a relação é menos assimétrica, com equilíbrio de formados entre homens e mulheres. No cômputo final, são $66,4 \%$ de formados do sexo masculino e 33,6\% do sexo feminino.

A presença expressiva de cursos de graduação nos centros urbanos do País (frequentados principalmente por homens) demonstra a força das metrópoles na formação em nível superior. Vicentini e Lugli (2009) e Mesquita e Soares (2011) afirmam que o desenvolvimento social e da administração do Brasil ocorreu eminentemente nos grandes aglomerados urbanos, por meio, também, da qualificação da mão de obra dos trabalhadores, responsáveis pelo desenvolvimento econômico da nação. São nesses territórios que também se concentram os maiores percentuais de matrículas da educação.

\section{O período 1998 - 2018: ampliando a oferta no interior e na capital}

A organização da licenciatura plena no Brasil se inicia com o advento das modificações legais ocorridas na década de 1990, sobretudo a LDB 9.394/96, que determina, também, a 
formação mínima para o exercício do magistério na educação básica (art. 62) e a década da educação (art. 87), no combate à escassez de professores habilitados para esta modalidade e, no caso em estudo, na área de Ciências e Matemática.

Vale destacar que, nessa mesma época, a educação básica no estado do Ceará tem seu processo de oferta ampliado, primeiro no ensino fundamental, com a universalização no fim dos anos 1990; e depois com o acelerado crescimento do ensino médio, iniciado nos primeiros anos do século XX e chegando ao seu pico em 2006.

O curso de licenciatura plena em Química da UECE foi concebido com o propósito de aumentar a quantidade de professores com qualificação exigida por lei para atuar na educação básica. Os dados apresentados no Quadro 3 permitem observar a quantidade de ingressantes no curso no período 1998 - 2018 e as respectivas situações acadêmicas.

Quadro 3 - Situação acadêmica dos alunos na licenciatura plena em Química no período 1998 - 2018

\begin{tabular}{|c|c|c|c|c|c|c|c|}
\hline $\begin{array}{c}\text { Ingres- } \\
\text { so }\end{array}$ & $\begin{array}{c}\text { Gradu- } \\
\text { ado }\end{array}$ & $\begin{array}{c}\text { Aban- } \\
\text { dono }\end{array}$ & $\begin{array}{c}\text { Desist- } \\
\text { ente }\end{array}$ & $\begin{array}{c}\text { Cance- } \\
\text { lado }\end{array}$ & $\begin{array}{c}\text { Desli- } \\
\text { gado }\end{array}$ & $\begin{array}{c}\text { Trans- } \\
\text { ferido }\end{array}$ & $\begin{array}{c}\text { Cursan- } \\
\text { do }\end{array}$ \\
\hline 5.102 & 1.470 & 1.761 & 466 & 67 & 50 & 154 & 1.134 \\
\hline
\end{tabular}

Fonte: Elaborado pelos autores com base nos dados fornecidos pelo DI da UECE (2018).

Neste período, ingressaram 5.102 alunos, uma média de 243 alunos por ano, sendo que 975 o fizeram a partir de 2015, o que inviabiliza a conclusão do curso num período menor do que quatro anos. Considerando tal aspecto, para efeitos dos cálculos sobre a situação acadêmica, optou-se por considerar os 4.127 alunos que ingressaram no período 1998 - 2014, conforme mostra o Gráfico 3

Gráfico 3 - Situação acadêmica dos alunos na licenciatura plena em Química no período 1998 - 2014

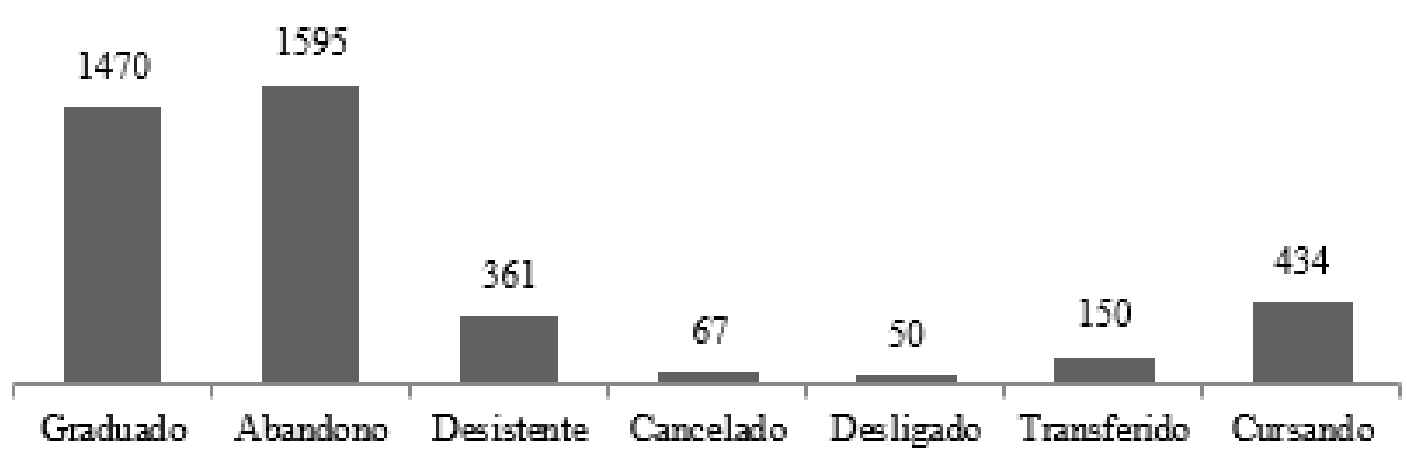

Fonte: Elaborado pelos autores com base nos dados fornecidos pelo DI da UECE (2018).

Do total de 4.127 ingressantes em 17 anos (1998 - 2014), 1.470 (35\%) conseguiram se graduar, 1.595 (39\%) abandonaram, 361 (9\%) desistiram, 434 (10\%) ainda estão cursando e 7\% pediram cancelamento, desligamento ou foram transferidos do curso. No que se refere aos percentuais de formados e dos que abandonaram o curso, os valores obtidos neste período 
são inferiores aos do período anterior. No entanto, o percentual de desistentes é superior, evidenciando assim que a natureza dos problemas do curso muda de foco, como evidenciado por Araújo e Vianna (2011) e Rabelo e Cavenagui (2016) sobre baixa conclusão e alta evasão nas licenciaturas na área de Ciências e Matemática. Ademais, estes resultados se alinham aos encontrados por Jesus, Araújo e Vianna (2014) sobre a eficiência da licenciatura em Química, refletindo sua incapacidade de formar parcelas mais expressivas de licenciados. Nos Gráficos 4 e 5, são apresentados os ingressantes e formados deste período por sexo.

Gráfico 4 - Ingressantes por sexo no

período 1998 - 2014
Gráfico 5 - Formados por sexo no

período 1998 - 2014

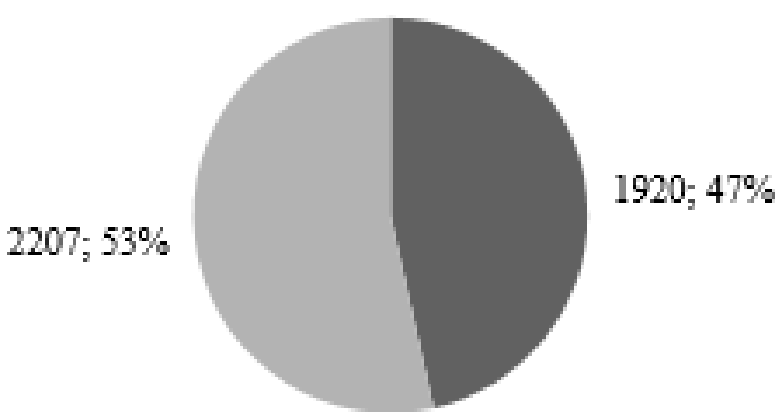

Masculino Eeminino

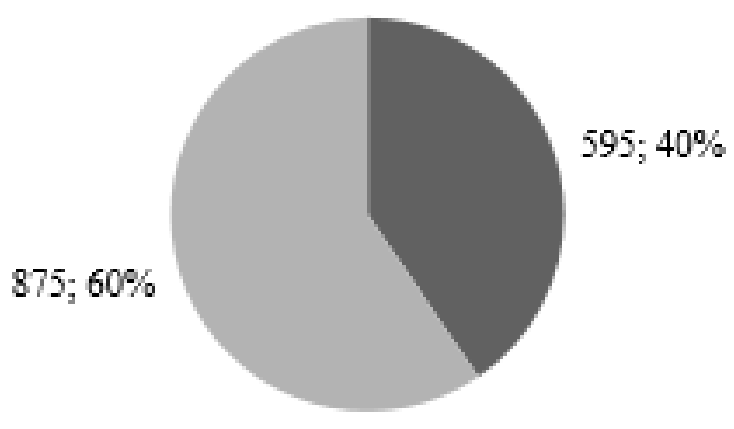

- Masculino Feminino
Fonte: Elaborado pelos autores com base nos dados fornecidos pelo DI da UECE (2018).
Fonte: Elaborado pelos autores com base nos dados fornecidos pelo DI da UECE (2018).

Quanto aos ingressantes, observa-se que 53\% são mulheres, um crescimento de 67,2\% em relação ao período anterior e 47\% de homens, uma redução de 31,2\% em relação ao mesmo período. Quando se analisa a quantidade de formados, o percentual de mulheres chega a $60 \%$ e o de homens, a 40\%. Esse fenômeno está associado à docência, pois segundo os dados contidos nas últimas Sinopses Estatísticas da Educação Superior no Brasil (INEP, 2017, 2018, 2019), a quantidade de estudantes ingressantes do sexo feminino no curso de licenciatura em Química é superior à quantidade de estudantes do sexo masculino, fato também observado em outros cursos de graduação em áreas afins da Química, como Engenharia Industrial, Química e Engenharia Química (BARRETO, 2014).

Sobre a presença feminina nos cursos de graduação no Brasil e, consequentemente, na profissão a qual se habilitou, Sampaio et al. (2002) afirmam que

As estatísticas mostram também que a docência na educação básica é uma atividade majoritariamente feminina, o que implica que a questão de gênero não pode ser ignorada como ocorre, mas incorporada como uma variável importante nas políticas e nos estudos da área. (SAMPAIO et al., 2002, p. 118). 
Guedes (2008) também destaca a feminização nos cursos de graduação na área de Ciência e Tecnologia. Por exemplo, em Química, a autora observou um aumento de 5\% de mulheres no período 1990 - 2000, o que levou a afirmar sobre "[...] um quadro mais amplo de mudanças nas relações de gênero, reforçando-as e estruturando-as ao instaurar novos elementos na realidade social" (p. 130).

Quando analisada a cartografia da oferta, tomando o período 1998 - 2014, os dados são apresentados no Quadro 4.

Quadro 4 - Relação de alunos ingressos e formados na licenciatura plena em Química no período 1998 - 2014

\begin{tabular}{|l|l|l|l|}
\hline Unidade & Quantidade de Ingressos & Quantidade de Formados & $\begin{array}{l}\text { Percentual de } \\
\text { Formados }\end{array}$ \\
\hline Fortaleza & 2.232 & 720 & $32,3 \%$ \\
\hline Crateús & 445 & 133 & $29,9 \%$ \\
\hline Itapipoca & 347 & 148 & $42,7 \%$ \\
\hline Limoeiro do Norte & 378 & 147 & $38,9 \%$ \\
\hline Quixadá & 425 & 189 & $44,5 \%$ \\
\hline Tauá & 300 & 133 & $44,3 \%$ \\
\hline Total & $\mathbf{4 . 1 2 7}$ & $\mathbf{1 . 4 7 0}$ & $\mathbf{3 5 , 6 \%}$ \\
\hline
\end{tabular}

Fonte: Elaborado pelos autores com base nos dados fornecidos pelo DI da UECE (2018).

Do total de ingressantes, $46 \%$ se dá nas unidades do interior da UECE, sendo que $51 \%$ dos formados encontram-se nessas unidades, evidenciando, portanto, uma maior taxa de êxito na conclusão do curso no interior. Os dados mostram que os maiores percentuais de formados ocorrem em Quixadá (44,5\%), Tauá (44,3\%) e Itapipoca (42,7\%), sendo os menores em Crateús (29,9\%) e Fortaleza (32,3\%).

Quando se considera a oferta por unidade da UECE, conforme o Gráfico 6, observase que $54 \%$ dos ingressantes o fazem em Fortaleza, 11\% em Crateús, 9\% em Itapipoca e em Limoeiro do Norte, 10\% em Quixadá e 7\% em Tauá, sendo que Itapipoca e Crateús são unidades que não aparecem na oferta do período 1976 - 1997, pois estes municípios não possuíam a oferta do curso de licenciatura curta em Ciências. 
Gráfico 6 - Ingressantes por unidade no período 1998 - 2014

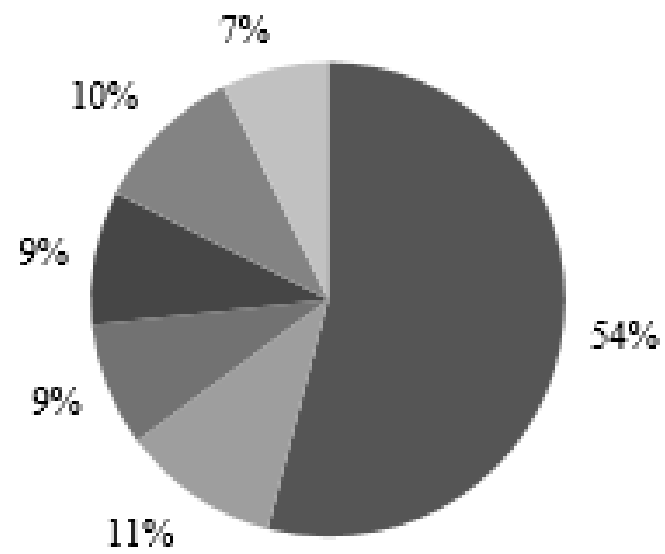

\author{
- Fortaleza \\ ๓Crateus \\ - Itapipoca \\ - Limoeiro do Norte \\ "Quixadá \\ "Taná
}

Fonte: Elaborado pelos autores com base nos dados fornecidos pelo DI da UECE (2018).

Isso confirma a prevalência da oferta de cursos de graduação em nível superior nos grandes centros urbanos do Brasil (VICENTINI; LUGLI, 2009; MESQUITA; SOARES, 2011), embora o interior do estado do Ceará já supere a sua capital na taxa de formação de licenciados em Química. Com relação aos formados por unidade da UECE e sexo, o Quadro 5 apresenta a situação no período 1998 - 2014.

Quadro 5 - Quantidade de formados por sexo na licenciatura plena em Química no período $1998-2014$

\begin{tabular}{|l|l|l|l|l|}
\hline \multirow{2}{*}{ Unidade } & \multicolumn{2}{|l|}{ Quantidade de Formados } & \multicolumn{2}{l|}{ Percentual de Formados } \\
\cline { 2 - 5 } & Masculino & Feminino & Masculino & Feminino \\
\hline Fortaleza & 299 & 421 & $41,5 \%$ & $58,5 \%$ \\
\hline Crateús & 51 & 82 & $38,3 \%$ & $61,7 \%$ \\
\hline Itapipoca & 70 & 78 & $47,3 \%$ & $52,7 \%$ \\
\hline Limoeiro do Norte & 51 & 96 & $34,7 \%$ & $65,3 \%$ \\
\hline Quixadá & 70 & 119 & $37,0 \%$ & $63,0 \%$ \\
\hline Tauá & 54 & $\mathbf{7 9}$ & $\mathbf{4 0 , 6 \%}$ & $59,4 \%$ \\
\hline Total & $\mathbf{5 9 5}$ & $\mathbf{8 7 5}$ & $\mathbf{4 0 , 5 \%}$ & $\mathbf{5 9 , 5 \%}$ \\
\hline
\end{tabular}

Fonte: Elaborado pelos autores com base nos dados fornecidos pelo DI da UECE (2018).

Se considerar a quantidade de formados por sexo, observa-se 40,5\% de homens e 59,5\% de mulheres. Quando se analisa a situação por unidade da UECE, 65,3\% dos formados em Limoeiro do Norte e 52,7\% de Itapipoca são mulheres, mostrando uma diferença de 12,6 pontos percentuais entre os valores maior e menor. Em relação ao período anterior, os dados deste período apresentam mudanças quanto ao sexo, tanto no ingresso como na formação, revelando uma maior taxa de sucesso por parte das mulheres - 53\% de ingressantes e quase $60 \%$ de formadas. 
Destarte, tanto as estatísticas atuais da Educação Superior no País como as constatações de Guedes (2008) e Barreto (2014) sobre a mudança no perfil do estudante de cursos de graduação das áreas de Ciência e Tecnologia se adéquam com os dados obtidos na licenciatura plena em Química da UECE. É possível inferir que este é também o comportamento apresentado no campo do magistério atualmente, como tem sido apontado por alguns estudos (FERREIRA; 1998; VIANNA; 2001/2002; UNESCO; 2004; PRÁ; CEGATTI; 2016).

\section{Considerações finais}

Este estudo mostrou que a formação de professores no Brasil é uma atividade dotada de momentos e circunstâncias peculiares que afetam significativamente a atuação docente na educação básica, especialmente na área de Ciências e Matemática. Problemas como a quantidade de licenciados e a qualidade da formação concedida ainda persistem, mesmo depois da implementação de políticas públicas diversas ao longo dos últimos 50 anos.

Desde sua origem, a UECE se destaca na formação de professores para os quadros de magistério da rede pública de educação básica do estado do Ceará, a prova é que, em quase quatro décadas, 8.314 estudantes ingressaram nos cursos de licenciatura curta em Ciências ou licenciatura plena em Química desta instituição. No caso do ensino na área de Química, dados atuais da Secretaria de Educação do estado do Ceará comprovam a importância desta universidade na qualificação destes profissionais: 51,8\% (342) dos 660 professores efetivos de Química lotados no ensino médio da rede pública estadual são provenientes da UECE (SEDUC, 2018). Os 318 graduados restantes foram formados em dezoito instituições, com destaque para a Universidade Federal do Ceará (UFC) (24,8\%) e a Universidade Estadual Vale do Acaraú (UVA) (16,7\%), ambas localizadas no Ceará.

Ainda assim, os resultados apresentados neste artigo evidenciam que os cursos analisados sofrem com percalços que atingem a área de Ciências e Matemática em relação à dificuldade de formar professores. Há evidências de altos percentuais de abandono, que superam os percentuais de formados, tanto no período de oferta da licenciatura curta, quanto no período subsequente. Registra-se, no entanto, uma modificação no perfil de procura pelo curso que vem sendo ofertado desde 1998, quando o percentual de mulheres se sobrepõe ao de homens, desmistificando que ciência e seu ensino são assuntos majoritariamente masculinos. Observamse também modificações na cartografia da oferta, com o aumento da interiorização, que responde por 45,9\% dos ingressantes e 51\% dos formados num período de dezesseis anos.

Este artigo representa um levantamento quantitativo sobre as licenciaturas em Ciências e em Química da UECE e seu potencial em formar professores. Entretanto, suscita questões que podem ser objeto de análises mais acuradas, viabilizadas por meio de pesquisas qualitativas e análises estatísticas mais sofisticadas com desagregação de dados, como no caso do abandono, da reprovação, do tempo de permanência para conclusão do curso que vem sendo ofertado e outras variáveis que podem ajudar a compreender sua oferta. 
ARAUJO, R. S.; VIANNA, D. M. A carência de professores de ciências e matemática na educação básica e a ampliação das vagas no ensino superior. Ciência \& Educação, Bauru, v. 17, n. 4, p. 807-822, 2011. DOI: dx.doi.org/10.1590/S1516-73132011000400003.

BARRETO, A. A mulher no ensino superior: distribuição e representatividade. Cadernos do GEA, Rio de Janeiro, n. 6, p. 1-52, jul./dez. 2014.

BRASIL. MEC. Fixa Diretrizes e Bases para o ensino de $1^{\circ}$ e $2^{\circ}$ graus, e dá outras providências. Lei $n^{\circ}$ 5.692, de 11 de agosto de 1971. Diário Oficial [da] República Federativa do Brasil, Poder Executivo, Brasília, DF, 12 ago. 1971. Seção 1, p. 6592. Disponível em: <http://www. planalto.gov.br/ccivil_03/leis/L5692.htm>. Acesso em: 10 mai. 2020.

BRASIL. MEC. Estabelece as diretrizes e bases da Educação nacional. Lei n 9.394 de 20 de dezembro de 1996. Diário Oficial [da] República Federativa do Brasil, Poder Executivo, Brasília, DF, 23 dez. 1996. Seção 1, p. 27833. Disponível em: <http://www.planalto.gov.br/ccivil_03/leis/ L9394.htm >. Acesso em: 06 abr. 2020.

BRASIL. MEC. Dispõe sobre a formação em nível superior de professores para atuar na educação básica, e dá outras providências. Decreto ${ }^{\circ} 3.276$, de 06 de dezembro de 1999. Diário Oficial [da] República Federativa do Brasil, Brasília, DF, 07 dez. 1999, Seção 1, p. 4. Disponível em: <http://www2.camara.leg.br/legin/fed/decret/1999/ decreto-3276-6-dezembro-1999369894-norma-pe.html>. Acesso em: 12 mar. 2020.

BRASIL. MEC/CNE. Escassez de professores no ensino médio: propostas estruturais e emergenciais. Brasília: MEC, 2007. Disponível em: http://portal.mec.gov.br/cne/arquivos/pdf/ escassez1.pdf. Acesso em: 15 mai. 2020.

FERREIRA, A. T. B. A Mulher e o Magistério. Razões da Supremacia Feminina. Tóp. Educ., Recife, v. 16, n. 1-3, p. 43-61, 1998.

GIL, A. C. Como elaborar projetos de pesquisa. 6. ed. São Paulo: Atlas, 2017.

GUEDES, M. C. A presença feminina nos cursos universitários e nas pós-graduações: desconstruindo a ideia da universidade como espaço masculino. História, Ciências, Saúde Manguinhos, Rio de Janeiro, v. 15, n. 3, p. 117-132, jun. 2008. DOI: dx.doi.org/10.1590/S010459702008000500006 .

INSTITUTO NACIONAL DE ESTUDOS E PESQUISAS EDUCACIONAIS ANÍSIO TEIXEIRA (Inep). Sinopse Estatística da Educação Básica 1997. Brasília: Inep, 1998. Disponível em: <http:// inep.gov.br/sinopses-estatisticas-da-educacao-basica>. Acesso em: 18 mai. 2020.

INSTITUTO NACIONAL DE ESTUDOS E PESQUISAS EDUCACIONAIS ANÍSIO TEIXEIRA (Inep). Censo escolar 2013: perfil da docência no ensino médio regular. Brasília: Inep, 2015. 110 p. Disponível em: <http://portal.inep.gov.br/documents/186968/484154/Censo+Escolar+2013++ Perfil + da +Doc\%C3\%AAncia + no +Ensino + M\%C3\%A9dio+Regular/da035f31-ce95-4cb5b43c-a4271ebb1cde?version=1.1 >. Acesso em: 02 mai. 2020.

INSTITUTO NACIONAL DE ESTUDOS E PESQUISAS EDUCACIONAIS ANÍSIO TEIXEIRA (Inep). Sinopse Estatística da Educação Superior 2017. Brasília: Inep, 2018. Disponível em: <http:// portal.inep.gov.br/basica-censo-escolar-sinopse-sinopse>. Acesso em: 12 mai. 2020. 
INSTITUTO NACIONAL DE ESTUDOS E PESQUISAS EDUCACIONAIS ANÍSIO TEIXEIRA (Inep). Sinopse Estatística da Educação Superior 2018. Brasília: Inep, 2019. Disponível em: <http:// portal.inep.gov.br/basica-censo-escolar-sinopse-sinopse>. Acesso em: 11 mai. 2020.

INSTITUTO NACIONAL DE ESTUDOS E PESQUISAS EDUCACIONAIS ANÍSIO TEIXEIRA (Inep). Resumo Técnico - Censo da Educação Básica 2018. Brasília: Inep, 2019. Brasília: Inep, 2019. Disponível em: <http://portal.inep.gov.br/basica-censo-escolar-sinopse-sinopse>. Acesso em: 10 mai. 2020.

JESUS, W. S; ARAUJO, R. S; VIANNA, D. M. Formação de professores de Química: a realidade dos cursos de Licenciatura segundo os dados estatísticos. Scientia Plena, v. 10, n. 8, p. 1-12, 2014.

LAMBRECHT, E. O.; ZARA, R. A. Impacto da ampliação das Vagas no Ensino Superior sobre a Formação de Professores de Física e Química para a Educação Básica. Ens. Tecnol. R., Londrina, v. 1, n. 2, p. 158-169, jul./dez. 2017. DOI: 10.3895/etr.v1n2.7374.

MESQUITA, N. A. S.; SOARES, M. H. F. B. Aspectos históricos dos cursos de licenciatura em química no Brasil nas décadas de 1930 a 1980. Química Nova, v. 34, n. 1, p. 165-174, 2011. DOI: dx.doi.org/10.1590/S0100-40422011000100031.

NASPOLINI, A. A reforma da educação básica no Ceará. Estudos Avançados, São Paulo, v. 15, n. 42, p. 169-186, mai./ago. 2001. DOI: dx.doi.org/10.1590/S0103-40142001000200006.

ORGANIZAÇÃO DAS NAÇÕES UNIDAS PARA EDUCAÇÃO, CIÊNCIA E CULTURA (UNESCO). 0 perfil dos professores brasileiros: o que fazem, o que pensam, o que almejam. São Paulo: Moderna, 2004.

PRÁ, J. R.; CEGATTI, A. C. Gênero, educação das mulheres e feminização do magistério no ensino básico. Revista Retratos da Escola, Brasília, v. 10, n. 18, p. 215-228, jan./jun. 2016. DOI: dx.doi.org/10.22420/rde.v10i18.660.

RABELO, R. P.; CAVENAGHI, S. M. Indicadores educacionais para formação de docentes: uso de dados longitudinais. Estudos em Avaliação Educacional, São Paulo, v. 27, n. 66, p. 816-850, set./dez. 2016. DOI: dx.doi.org/10.18222/eae.v0ix.4084.

SÁ, C. S. S.; SANTOS, W. L. P. Licenciatura em Química: carência de professores, condições de trabalho e motivação pela carreira docente. In: Encontro Nacional de Pesquisa em Educação em Ciências, VIII, 2011, Campinas-SP. Anais do VIII ENPEC. Águas de Lindóia: ABRAPEC, 2011. p. 1-12

SAMPAIO, C. E. M. SOUSA, C. P.; SANTOS, J. R. S.; PEREIRA, J. V.; PINTO, J. M. R.; OLIVEIRA, L. L. N. A.; MELLO, M. C.; NÉSPOLI, V. Estatísticas dos professores no Brasil. Revista Brasileira de Estudos Pedagógicos, v. 83, n. 203/204/205, p.85-120, 2002. DOI: doi.org/10.24109/21766681.rbep.83i203-04-05.907.

SECRETÁRIA DE EDUCAÇÃO DO ESTADO DO CEARÁ (Seduc). Dados solicitados pelo Portal da Transparência. 2018.

VIANNA, C. P. O sexo e o gênero da docência. Cadernos Pagu, v. 17/18, p. 81-103, 2001/2002. DOI: dx.doi.org/10.1590/S0104-83332002000100003.

VICENTINI, P. P.; LUGLI, R. G. História da profissão docente no Brasil: representações em disputa. São Paulo: Cortez, 2009. 
YIN, R. K. Estudo de Caso: planejamento e métodos. Trad. HERRERA, C. M. 5 ed. Porto Alegre: Bookman, 2015.

\section{Notas}

1 Quando houve a junção das faculdades isoladas para criação da UECE, já existia a Faculdade de Matemática e de Filosofia, que se incorporaram de imediato. A licenciatura curta em Ciências foi o primeiro curso de formação de professores criado depois da institucionalização da UECE.

2 Embora a licenciatura curta em Ciências tenha realizado seu último ingresso em 1997, sua extinção definitiva só ocorre alguns anos depois, devido a um contingente de alunos que estavam matriculados no curso e ainda não o concluíra. A UECE criou mecanismos que possibilitavam a opção pelas novas licenciaturas plenas e também definiu estratégias de migração de um currículo para outro, bem como sistema de equivalências. 